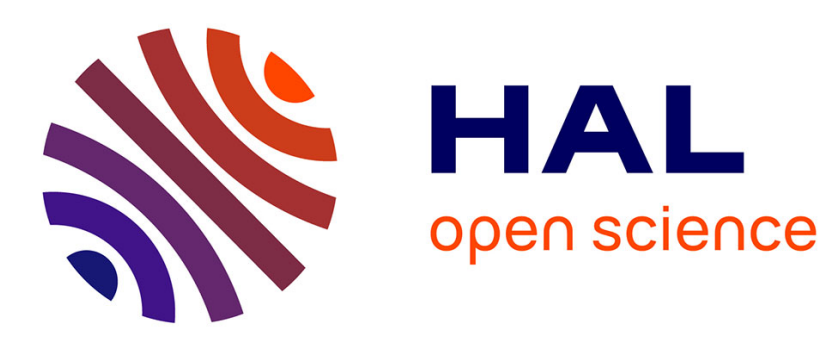

\title{
Accurate analysis of mechanical stress in dielectric multilayers
}

Thomas Begou, Julien Lumeau

\section{To cite this version:}

Thomas Begou, Julien Lumeau. Accurate analysis of mechanical stress in dielectric multilayers. Optics Letters, 2017, 42 (16), pp.3217-3220. 10.1364/OL.42.003217 . hal-01575558

\section{HAL Id: hal-01575558 \\ https://hal.science/hal-01575558}

Submitted on 26 Mar 2019

HAL is a multi-disciplinary open access archive for the deposit and dissemination of scientific research documents, whether they are published or not. The documents may come from teaching and research institutions in France or abroad, or from public or private research centers.
L'archive ouverte pluridisciplinaire HAL, est destinée au dépôt et à la diffusion de documents scientifiques de niveau recherche, publiés ou non, émanant des établissements d'enseignement et de recherche français ou étrangers, des laboratoires publics ou privés. 


\title{
Accurate analysis of mechanical stress in dielectric multilayers
}

\author{
Thomas Begou, ${ }^{1, *}$ AND JULIEN LUMEAU ${ }^{1}$ \\ ${ }^{1}$ Aix Marseille Univ, CNRS, Centrale Marseille, Institut Fresnel, F-13013 Marseille, France \\ *Corresponding author: Thomas.begou@fresnel.fr
}

Received XX Month XXXX; revised XX Month, XXXX; accepted XX Month XXXX; posted XX Month XXXX (Doc. ID XXXXX); published XX Month XXXX

\begin{abstract}
We present a systematic study of stress coefficient of dielectric materials $\left(\mathrm{SiO}_{2}, \mathrm{Nb}_{2} \mathrm{O}_{5}\right.$ and $\left.\mathrm{HfO}_{2}\right)$. In particular, we show a thickness dependence of the stress coefficient on layer thickness which shows that the determination of this coefficient is complex and requires careful analysis. We then apply the different models of stress coefficient to multilayer structures and show that stress-induced deformation can be precisely predicted in final components with a few percent accuracy.
\end{abstract}

OCIS codes: (310.4925) Other properties (stress, chemical, etc.); (310.3840) Materials and process characterization; (310.1620) Interference coatings.

Optical interference filters are key elements in a broad range of applications including telecom, biophotonics, lasers, medical... With recent advances in the technology of thin film filters fabrication, the complexity of the fabricated functions has severely increased and it is therefore now common to fabricate components having several hundreds of layers. However, the deposition of layers on top of a substrate with different properties are known to produce internal residual mechanical stresses that can result in significant deformation of the substrate after fabrication, the thicker the multilayer coating, the larger this deformation. It is thus clear that for demanding applications, stress-induced deformation has become a major challenge that needs to be tackled [1]. Indeed, as of today, there are wide range of applications requiring flat optical components with specifications on final surface flatness that must be within a few nanometers or few tens of nanometers. These applications include gravitational wave detections [2], linear accelerators [3,4], or space applications [5]. There are two concurrent approaches to solve this problem. The first one consists in controlling stress induced deformation by adapting deposition parameters such as temperature [6], post-processing of the fabricated components like thermal annealing [7], altering the moisture content of the film with water-diffusion barriers [8] or combining materials with compressive and tensile stresses [9]. However, such approaches are not always possible for all thin film materials and, in addition, this might be a problem when fabricating complex optical interference filters as final filter performances can be affected by these methods. An alternative method consists in compensating stress-induced deformation by dual side optical coating
[10]. While this approach is very versatile, it is in practice hard to apply to obtain perfect stress compensation as exact knowledge on the mechanical stress induced in thin films is required and determination of these effects is not easily achieved [11-12]. To make this determination and include it into the design of optical coatings with stress control, R. Willey has recently proposed a detailed method on how to achieve it [13]. However, the conclusions of this paper were that it does not exist comprehensive determination of these parameters. In order to provide a first answer to this need and evaluate the accuracy of stress compensation method by dual side coating, we present in this paper a precise characterization of the stress in single layers. We then develop an accurate model that we apply to the determination of stress induced deformation in multilayers in order to accurately predict the flatness of the final component.

Stress induced deformation in optical coatings is a classical effect that appears every time a layer is deposited on top of a substrate. This effect is principally due to a mismatch of the coefficient of thermal expansion of the substrate and the films, but is also affected by other intrinsic factors such as the layer thickness, the deposition temperature, the deposition rate, the deposition pressure. It is finally very dependent on the layer fabrication technology (e-beam, ion assisted deposition, magnetron sputtering, ion beam sputtering...) and deposition parameters (material, assistance parameters...). The most common materials for the fabrication of complex optical interference filters in visible and near-IR ranges are $\mathrm{SiO}_{2}$ for low index materials, and high refractive index materials include $\mathrm{Nb}_{2} \mathrm{O}_{5}, \mathrm{Ta}_{2} \mathrm{O}_{5}$ and $\mathrm{HfO}_{2}$ (ordered with decreasing refractive indices and increasing bandgap). While $\mathrm{Ta}_{2} \mathrm{O}_{5}$ used to be the material of choice for most of optical filters in early 2000 [14], $\mathrm{Nb}_{2} \mathrm{O}_{5}$ has now, most of the time, supplanted $\mathrm{Ta}_{2} \mathrm{O}_{5}$ for complex multilayer stacks as it provides a larger refractive index contrast [15] while $\mathrm{HfO}_{2}$ is generally used for high power laser or UV applications [16]. We thus restricted our study to $\mathrm{SiO}_{2}, \mathrm{Nb}_{2} \mathrm{O}_{5}$ and $\mathrm{HfO}_{2}$. Table 1 presents a short literature survey of stress values measured for these materials where tensile stress is positive and compressive stress is negative. We see that there is a broad range of values even for layers of the same materials but deposited with different technologies or conditions. Therefore, we see that in order to carry out a precise determination of stress induced in single layers, it is mandatory to use a stable and repeatable thin film fabrication method.

In our study, we opted for the manufacturing of single or multilayers components with a HELIOS 4" machine, developed by Bühler/Leybold Optics, where low and high refractive index materials were both deposited using Plasma Assisted Reactive Magnetron Sputtering 
(PARMS) $[15,16]$. This choice is motivated by the fact that this technology has proven to be one of the best choices when it comes to the deposition of complex (and thick) multilayer coatings and therefore when large stress induced deformation becomes a major problem. In addition, it is well known that sputtering is a very stable and repeatable technology making it a technique of choice for our study. Typical deposition rates of low and high index materials were respectively $0.35 \mathrm{~nm} . \mathrm{s}^{-1}$ and $0.50 \mathrm{~nm} . \mathrm{s}^{-1}$ with deviation from this rates not exceeding $\pm 0.02 \mathrm{~nm} . \mathrm{s}^{-1}$, which means that less than an atomic layer of material was deposited at each rotation of the turn-table. Thicknesses of the different deposited layers were optically monitored, in a transmission mode, at a precisely selected wavelength through the Optical Monitoring System OMS5000 developed by Bühler/Leybold Optics [17]. Moreover, the presence of a load lock allowed to remove or add samples anytime during the deposition process, without exposing to air all the samples in the machine and breaking the manufacturing process. We thus extensively used it during our study in order to allow studying how stress is building up while layer is growing on the substrate. Indeed, all the samples, covered with the same material, were processed in the same batch and added progressively to obtain different film thicknesses. This ensured obtaining reliable and consistent data.

Tab. 1. Typical stress parameters of $\mathrm{SiO}_{2}, \mathrm{Nb}_{2} \mathrm{O}_{5}$ and $\mathrm{HfO}_{2}$ layers (from literature). IAD - Ion Assisted Deposition, PIAD Plasma Ion Assisted Deposition, MS - Magnetron Sputtering and PARMS - Plasma-Assisted Reactive Magnetron Sputtering

\begin{tabular}{|c|c|c|c|}
\hline Material & Stress coefficient & Technique & Reference \\
\hline \multirow[t]{4}{*}{$\mathrm{SiO}_{2}$} & $-270 \mathrm{MPa}$ & MS & [7] \\
\hline & $\begin{array}{l}-435 \mathrm{MPa} \\
-267 \mathrm{MPa}\end{array}$ & $\begin{array}{l}\text { PARMS } \\
\text { PIAD }\end{array}$ & [17] \\
\hline & $-1012 \mathrm{MPa}$ & IBS & [18] \\
\hline & $\begin{array}{l}-110 \mathrm{MPa} \\
-262,-529 \mathrm{MPa}\end{array}$ & $\begin{array}{l}\text { MS } \\
\text { PIAD }\end{array}$ & [19] \\
\hline \multirow[t]{5}{*}{$\mathrm{Nb}_{2} \mathrm{O}_{5}$} & $-30 \mathrm{MPa}$ & MS & [7] \\
\hline & $-138,-190 \mathrm{MPa}$ & PARMS & [17] \\
\hline & $-966 \mathrm{MPa}$ & IBS & [18] \\
\hline & $-517 \mathrm{MPa}$ & IBS & [20] \\
\hline & $\begin{array}{l}-80,-132 \mathrm{MPa} \\
-52,+163\end{array}$ & $\begin{array}{l}\text { MS } \\
\text { PIAD }\end{array}$ & [19] \\
\hline \multirow[t]{2}{*}{$\mathrm{HfO}_{2}$} & $-230 \mathrm{MPa}$ & IBS & [6] \\
\hline & $-117, \mathrm{MPa}$ & PIAD & [19] \\
\hline
\end{tabular}

In order to extract the stress coefficient of thin film materials, another very important aspect is the method used for extracting the deformation. An important reason for the wide range of stress coefficient values is not only the intrinsic fluctuations of this coefficient but also measurement errors. For example, Stenzel and al. stated that in case of very thick samples, their absolute error on stress determination is surely below $50 \mathrm{MPa}$ [21]. This value is non negligible and represents at least $10 \%$ errors on the stress value. In addition, it means that stress can only be determined for thick layers and not for thin layers as the one used for a regular multilayer stack. In practice, this is not a problem as stress is generally supposed to be constant in the regime of thin films. In our case, we optimized our metrology in order to decrease our error to the lowest possible value. We measured the flatness by white light interferometry using a Zygo NewView 7300 with a $1 \times$ objective. In these conditions, the measured aperture is about $14 \times 10 \mathrm{~mm}^{2}$. In order to measure the whole sample aperture, we used stitching method provided by Zygo Metropro software. At this stage, it is worth noting that such an instrument is better adapted to the measurement of roughness while flatness is generally measured using a Fizeau interferometer. However, in our case, as we wanted to measure samples with one coated surface, low coherence reflectometry as provided by the Zygo NewView appeared as a more appropriate technique as it allows separating the contribution of both surfaces thanks to the limited coherence length [22]. In addition, in order to take into account aberrations in the measuring optical system, we calibrated all the measurements using a SiC etalon. Using this rigorous approach, flatness measurement errors could be limited to a few percent. For each experiment, two samples were coated simultaneously and both coated and uncoated surfaces (having the same deformation with opposite sign) were measured after deposition in order to calculate average values and limit measurement errors.

The coatings were performed on fused silica substrates with diameter of $25 \mathrm{~mm}$ and thickness of $1 \mathrm{~mm}$, polished to flatness better than $\lambda / 4$ at $633 \mathrm{~nm}$. In order to take into account the initial curvature of the substrates, flatness was measured before coating. In addition, the exact physical thickness of each of the samples was also measured using a calibrated caliper with precision of $1 \mu \mathrm{m}$. Such precautions are mandatory to secure high stress determination accuracy. Finally, the exact thickness of each coatings was extracted from spectrophotometric measurement using a Perkin Elmer Lambda 1050 combined with reverse engineering algorithm. The precision on the thickness of each layer was about $\pm 5 \mathrm{~nm}$.

For each of the chosen materials $\left(\mathrm{SiO}_{2}, \mathrm{Nb}_{2} \mathrm{O}_{5}\right.$ and $\left.\mathrm{HfO}_{2}\right)$, single layers with different thicknesses were deposited using the previously described method. For each batch of sample, we measured the following parameters:

- the substrate thickness ts,

- the radius of curvature of the substrate before deposition Rs,

- the radius of curvature of the substrate after deposition $\mathrm{R}_{\mathrm{S}+\mathrm{f} \text {, }}$

- $\quad$ the layer thickness $t_{\text {f.. }}$

Stoney equation was then applied to extract the stress coefficient of each of the fabricated material [23]:

$$
\sigma=\frac{E_{S} T_{S}^{2}}{6 t_{f}\left(1-v_{S}\right)}\left(\frac{1}{R_{S+f}}-\frac{1}{R_{S}}\right)
$$

where $\boldsymbol{E}_{\boldsymbol{S}}$ and $\boldsymbol{v}_{\boldsymbol{s}}$ stand respectively for the Young modulus and the Poisson coefficient of the substrate, in our case fused silica $\left(\boldsymbol{E}_{s}=73 \mathrm{GPa}\right.$ and $\boldsymbol{v}_{\boldsymbol{s}}=0.16$ ). Equation 1 was then redefined to simply extract the information on the stress value:

$$
\frac{K_{S}}{R_{\text {Norm }}}=\sigma\left(t_{f}\right) t_{f}
$$

where

$$
K_{S}=\frac{E_{S}}{6\left(1-v_{S}\right)}
$$

and is a constant term that depends on the mechanical properties of the substrate,

$$
R_{\text {Norm }}=\frac{R_{S} R_{S+f}}{t_{S}^{2}\left(R_{S}-R_{S+f}\right)}
$$

is the radius of curvature, normalized to the substrate thickness, and directly induced by the deposited layer. We finally considered in this study that tensile stress is positive and compressive stress is negative. By plotting the $\mathrm{Ks} / \mathrm{R}_{\text {Norm }}$ dependence on film thickness for $\mathrm{SiO}_{2}, \mathrm{Nb}_{2} \mathrm{O}_{5}$ and $\mathrm{HfO}_{2}$ layers (Figure 1), it is thus possible to extract the stress coefficient for each of the studied materials.

At first, we considered the classical approach consisting in considering that the mechanical stress coefficient is constant for a given material and is independent on film thickness: $\boldsymbol{\sigma}_{\mathrm{i}}=\boldsymbol{K}_{\boldsymbol{i}}$ [24] ( $\boldsymbol{i}$ stands for either $\mathrm{SiO}_{2}, \mathrm{Nb}_{2} \mathrm{O}_{5}$ or $\mathrm{HfO}_{2}$ ). Table 2 provides the values of the fitting data. One can immediately see that all layers provide compressive stress, and that such a classical model allows accurately fitting the curves in Figure 1 for $\mathrm{SiO}_{2}$ and $\mathrm{Nb}_{2} \mathrm{O}_{5}$, but is completely wrong for $\mathrm{HfO}_{2}$. In order to correct for this deviation from linearity, we then considered a second order polynomial to fit the experimental 

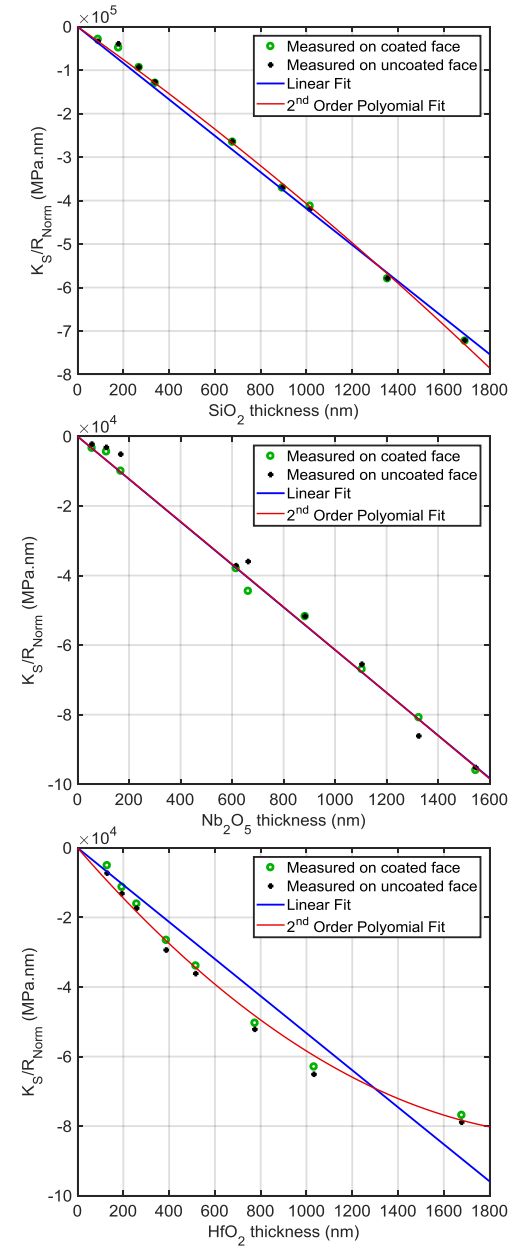

Fig. 1. Normalized radius of curvature evolution as a function of film thickness for $\mathrm{SiO}_{2}$ (top), $\mathrm{Nb}_{2} \mathrm{O}_{5}$ (middle) and $\mathrm{HfO}_{2}$ (bottom). Linear fit (blue line) and second order polynomial fit (red line).

data. This approach is similar to the one developed by Nordin et al. [25] who considered that stress can be modeled by equations of the form of an offset constant and a linear term in thickness. We thus considered a dependence of the stress coefficient on thickness (expressed in nanometers) following:

$$
\sigma_{i}=A_{i}+B_{i} t_{i}
$$

Table 2 provides the values of fitting data. It also provides a value of the merit function that allows estimating the quality of the fit and is defined as:

$$
M F=\frac{1}{N} \sqrt{\sum_{i=1}^{N}\left(X_{\text {mod }}-X_{\text {exp }}\right)^{2}}
$$

where $\boldsymbol{N}$ is the number of data points and $\boldsymbol{X}$ stands for $\boldsymbol{K}_{\boldsymbol{s}} / \mathbf{R N o r m}_{\bmod }$ (theoretical points) and $\boldsymbol{K}_{\boldsymbol{S}} / \boldsymbol{R N N o r m}_{\exp }$ (experimental data). One can see in Figure 1 that for $\mathrm{Nb}_{2} \mathrm{O}_{5}$, the non-linear model does not severely change the visual fit of experimental data and this is confirmed by similar MF for both type of modeling. For $\mathrm{SiO}_{2}$, the use of a non-linear model appears to better fit the experimental data and this trend is confirmed by a decrease of the MF by $\sim 40 \%$. We can see that in case of $\mathrm{HfO}_{2}$, non-linear model allows to account for the decrease of stress induced deformation on film thickness and this is confirmed by a large decrease of the MF by three times. One can notice that the sign of the $\mathrm{B}$ coefficient is different for $\mathrm{HfO}_{2}$ compared to $\mathrm{Nb}_{2} \mathrm{O}_{5}$ and $\mathrm{SiO}_{2}$. In addition, the largest decrease of stress coefficient on film thickness is not obtained for the material having the largest initial stress coefficient showing that stress relaxation is a complicated process and therefore accurate determination is mandatory to precisely control deformation in thin film optical elements. Finally, it is worth mentioning that such a fine analysis of the experimental data could only be achieved because we implemented a rigorous and repeatable procedure for the characterization of all fabricated samples. However, one can see that for thin layer thickness as the one commonly used in multilayer stacks for visible and near-IR ranges, the determination precision is not enough to allow perfect fit of all data. This can be easily understood that for layers with a few tens of nanometer, the deformation/sag is only a few tens of nanometers and determination of the radius of curvature is therefore uneasy even more if initial sample flatness is not with perfect spherical symmetry. To validate these data, it is thus mandatory to analyze how the proposed model applies to multilayer structures.

Tab. 2. Stress parameters obtain from a linear fit and from a second order polynomial fit.

\begin{tabular}{cccccc}
\hline & \multicolumn{2}{c}{ Linear fit } & \multicolumn{3}{c}{ 2nd order polynomial fit } \\
\cline { 2 - 6 } Material & $\boldsymbol{K}$ & $\boldsymbol{M F}$ & $\boldsymbol{A}$ & $\boldsymbol{B}$ & $\boldsymbol{M F}$ \\
& $(\mathrm{MPa})$ & $(\mathrm{MPanm})$ & $(\mathrm{MPa})$ & $\left.(\mathrm{MPa.nm})^{-1}\right)$ & $(\mathrm{MPa} . n \mathrm{n})$ \\
\cline { 3 - 6 } $\mathbf{S i O}_{2}$ & $\mathbf{- 4 1 8 . 5}$ & 5154 & $\mathbf{- 3 7 1 . 2}$ & $\mathbf{- 0 . 0 3 6 0}$ & 3064 \\
$\mathbf{N b}_{2} \mathbf{O}_{5}$ & $\mathbf{- 6 1 . 4}$ & 599 & $\mathbf{- 6 1 . 0}$ & $\mathbf{- 0 . 0 0 0 3}$ & 599 \\
$\mathbf{H f O}_{2}$ & $\mathbf{- 5 3 . 3}$ & 2463 & $\mathbf{- 7 6 . 4}$ & $\mathbf{+ 0 . 0 1 7 8}$ & 878 \\
\hline
\end{tabular}

We studied the evolution of stress while fabricating structures with alternated high and low refractive index materials with optical thickness equal to a quarter wave at $532 \mathrm{~nm}$. This structure is the one of a classical quarter wave dielectric mirrors. To precisely study the effect of stress on substrate deformation we opted for a 21-layer quarter-wave mirror $\left((\mathrm{HL})^{10} \mathrm{H}\right)$, with $\mathrm{Nb}_{2} \mathrm{O}_{5}$ as high index material $(\mathrm{H})$ and $\mathrm{SiO}_{2}$ as low index material (L). Such a mirror results in high reflectivity at $532 \mathrm{~nm}$ of $\sim 99.99 \%$. In order to test the different models of the stress in single layers, we characterized the mirror deformation during its construction. To achieve this, we inserted 7 different substrates in 7 different slots of the HELIOS deposition machine and removed progressively, thanks to the load-lock, one of the sample at achievement of the following mirrors: M5, M9, M11, M15, M17, M19 and M21, the number referring to the total number of layers of the mirrors, without perturbing the process. With this procedure, all the samples were processed within the same batch. We measured the spectral dependence of reflection of each of the fabricated mirrors and checked, using reverse engineering, that the average error of the thickness of each layer does not exceed $0.5 \%$. We then re-measured the flatness of each of the fabricated mirrors using the ZYGO NewView and plotted the dependence of the sag (in nanometers) on the number of deposited layers (Figure 2).

In order to model the experimental data, we assumed that the $\mathbf{K} \mathbf{S} / \mathbf{R}_{\mathbf{N o r m}}$ ratio evolves as expressed in equation $7 . \mathbf{N}_{\mathbf{H}}$ and $\mathbf{N}_{\mathbf{L}}$ are respectively the number of high $(\mathbf{H})$ and low (L) refractive index material layers in the structure:

$$
\frac{K_{S}}{R_{\text {Norm }}}=\sum_{i=1}^{N_{H}} \sigma_{H}\left(t_{H i}\right) t_{H i}+\sum_{i=1}^{N_{L}} \sigma_{L}\left(t_{L i}\right) t_{L i}
$$

In order to better quantify and analyze the deformation of the substrates after deposition, we focused our study on the sag of the sample after deposition. In that case, we could first write again equation (7) in a different way to extract the experimental value of RNorm.

$$
R_{\text {Norm }}=\frac{K_{S}}{\sum_{i=1}^{N_{H}} \sigma_{H}\left(t_{H i}\right) t_{H i}+\sum_{i=1}^{N_{L}} \sigma_{L}\left(t_{L i}\right) t_{L i}}
$$




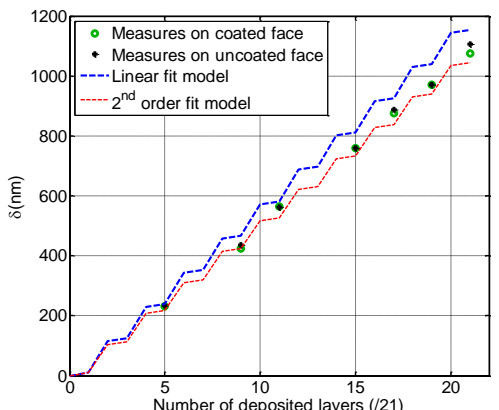

Fig. 2. Evolution of $K_{S} / R_{\text {Norm }}$ as a function of the number of deposited layers for a M21 mirror centered at $532 \mathrm{~nm}$.

Then from this experimental normalized radius of curvature we could calculate the sag.

$$
\delta=R_{\text {Norm }} \pm \sqrt{R_{\text {Norm }}^{2}-\left(\frac{D_{S}}{2}\right)^{2}}
$$

where minus sign is used if stress is compressive and plus sign if stress is tensile. In Figure 2, we plotted, in addition to the experimental data measured on both sides of the substrate at different steps of the mirror under fabrication, the sag calculated using the two models of stress, i.e. either constant or with a dependence on layer thickness (equation (8)). Using constant stress, it is seen that the model overestimates the deformation by about $10 \%$. The resulting MF is 19.5 $\mathrm{nm}$. However, when the stress model that takes into account a stress dependence on thickness is used, we can see that the evolution of sag on number of deposited layers becomes more accurate with a deviation for each point not exceeding a few percent resulting in a MF of $10.9 \mathrm{~nm}$. We therefore see that this accurate model enables precise modeling of the stress induced deformation by any single or multilayer structures.

To further confirm this approach we studied various types of optical components having different types of structures and thicknesses:

1. A bilayer composed with a $\mathrm{SiO}_{2}$ layer and a $\mathrm{Nb}_{2} \mathrm{O}_{5}$ layer with thickness equal to the total thickness used for the M21 mirror at $532 \mathrm{~nm}(11 \mathrm{H} 10 \mathrm{~L})$

2. A mirror composed with 21 alternated $\mathrm{SiO}_{2}$ and $\mathrm{Nb}_{2} \mathrm{O}_{5}$ layers centered at $532 \mathrm{~nm}$. In this case, due to stress thickness dependence, sag value is different from the bilayer.

3. A mirror composed with $\mathrm{SiO}_{2}$ and $\mathrm{HfO}_{2}$ layers, with a total of 33 alternated layers and centered at $532 \mathrm{~nm}$.

4. A complex filter composed with 70 layers made of $\mathrm{SiO}_{2}$ and $\mathrm{Nb}_{2} \mathrm{O}_{5}$, with thicknesses varying from 40 to $610 \mathrm{~nm}$.

5. A bandpass filter centered at $600 \mathrm{~nm}$ rejecting on a 400-1200 $\mathrm{nm}$ range composed with 105 layers made of $\mathrm{SiO}_{2}$ and $\mathrm{Nb}_{2} \mathrm{O}_{5}$, with thicknesses ranging from 30 to $250 \mathrm{~nm}$.

Tab. 3. Calculation and measurement of stress-induced deformation in various optical components.

\begin{tabular}{|r|r|r|r|r|r|r|r|}
\hline$\#$ & $\begin{array}{c}\mathbf{T}_{\mathbf{H}} \\
\mathbf{n m}\end{array}$ & \multicolumn{1}{|c|}{$\begin{array}{c}\mathbf{T}_{\mathbf{B}} \\
\mathbf{n m}\end{array}$} & \multicolumn{1}{|c|}{$\begin{array}{c}\mathbf{T}_{\mathbf{T}} \\
\mathbf{n m}\end{array}$} & \multicolumn{1}{c|}{$\mathbf{N}$} & \multicolumn{1}{c|}{$\begin{array}{c}\boldsymbol{\delta}_{\text {meas. }} \\
\mathbf{n m}\end{array}$} & \multicolumn{1}{c|}{$\begin{array}{c}\boldsymbol{\delta}_{\text {calc. }} \\
\mathbf{n m}\end{array}$} & $\begin{array}{c}\text { Relative } \\
\text { error }\end{array}$ \\
\hline $\mathbf{1}$ & 615 & 895 & 1510 & $\mathbf{2}$ & $\mathbf{1 0 9 6 . 7}$ & $\mathbf{1 0 9 1 . 1}$ & $0.5 \%$ \\
\hline $\mathbf{2}$ & 615 & 895 & 1510 & $\mathbf{2 1}$ & $\mathbf{9 9 8 . 3}$ & $\mathbf{1 0 0 2 . 2}$ & $-0.4 \%$ \\
\hline $\mathbf{3}$ & 1100 & 1430 & 2530 & $\mathbf{3 3}$ & $\mathbf{1 5 6 7 . 9}$ & $\mathbf{1 4 3 1 . 6}$ & $9.0 \%$ \\
\hline $\mathbf{4}$ & 2270 & 4550 & 6820 & $\mathbf{7 0}$ & $\mathbf{5 1 9 9 . 0}$ & $\mathbf{5 0 5 6 . 2}$ & $2.8 \%$ \\
\hline $\mathbf{5}$ & 4640 & 6730 & 11300 & $\mathbf{1 0 5}$ & $\mathbf{7 4 7 2 . 3}$ & $\mathbf{6 9 9 4 . 8}$ & $6.6 \%$ \\
\hline
\end{tabular}

These optical components were fabricated using the HELIOS machine. Spectral characterization were performed in order to secure that minimal errors have been carried. We then measured the deformation (sag) of the substrates after deposition and compared these data to theoretically calculated data (Table 3). We see that the developed model allows accurately characterizing various optical elements composed with a wide range of coating thicknesses.

We have validated an accurate thickness-dependent model for the stress induced in $\mathrm{SiO}_{2}, \mathrm{Nb}_{2} \mathrm{O}_{5}$ and $\mathrm{HfO}_{2}$ layers deposited by plasma assisted reactive magnetron sputtering (PARMS). This model was used to predict the evolution of the deformation of a dielectric mirror under manufacturing. From this accurate modeling, and the initial substrate deformation, it is thus possible to design a thin film stack that minimizes the deformation of the final component.

Acknowledgment. We acknowledge ALSYOM Company and CNRS-LAL for fruitful discussions and collaboration.

\section{References}

1. Milton Ohring, Materials science of thin films (1992)

2. https://www.ligo.caltech.edu/news/ligo20160211.

3. O. Adriani, et al., Technical Design Report EuroGammaS proposal for the ELI-NP Gamma beam System, LAL/RT 14-63 (2014).

4. C. A. Ur, AIP Conference Proceedings 1645, 237 (2015).

5. M.-M. de Denus-Baillargeon, T. Schmitt, S. Larouche, and L. Martinu, Appl. Opt. 53, 2616 (2014).

6. Y. Wang, Y. Zhang, W. Chen, W. Shen, X. Liu, and P. Gu, Appl. Opt. 47, C319 (2008).

7. M. Bischoff, T. Nowitzki, O. Voß, S. Wilbrandt, O. Stenzel, Appl. Opt. 53, A212 (2014)

8. F Richter, H Kupfer, P Schlott, T Gessner, C Kaufmann, Thin Solid Films 389(1-2), 278 (2001).

9. J. B. Oliver, P. Kupinski, A. L. Rigatti, A. W. Schmid, J. C. Lambropoulos, S. Papernov, A. Kozlov, C. Smith, and R. D. Hand, Opt. Express 20, 1659616610 (2012)

10. F. Lemarquis, Appl. Opt. 53, A229. (2014).

11. T. Begou, H. Krol, D. Stojevski, F. Lemarchand, M. Lequime, C. GrezesBesset and J. Lumeau, CEAS Space J, in Press (2017).

12. T. Amotchkina, M. Trubetskov, Y. Pervak, L. Veisz, and V. Pervak, Opt. Express 22, 30387 (2014)

13. R. Willey, Society of Vacuum Coaters Annual Technical Conference Proceedings 57 (2014)

14. R. B. Sargent and N. A. O'Brien, MRS Bulletin 28(5) 372, May 2003.

15. T. Begou, F. Lemarchand and J. Lumeau, Opt. Express 24(18), 2092520937 (2016).

16. M. Scherer, J. Pistner, and W. Lehnert, in Optical Interference Coatings, OSA Technical Digest,paper MA7 (2010).

17. A. Zoeller, M. Boos, H. Hagedorn, W. Klug, and C. Schmitt, in Optical Interference Coatings, OSA Technical Digest Series, paper TuE10 (2004).

18. S. Jakobs, M. Lappschies, U. Schallenberg, O. Stenzel, and S. Wilbrandt, Chinese Optics Letters 8, 1 (2010)

19. R. Chow, M.A. Schmidt, A.W. Coombs, J. Anguita, M.J. Thwaites, 49th Annual SVC Technical Conference Washington, DC, United States, 2006

20. C.-C. Lee, C.-L. Tien, and J.-C. Hsu, Appl. Opt. 41, 2043 (2002)

21. O. Stenzel, S. Wilbrandt, N. Kaiser, M. Vinnichenko, F. Munnik, A. Kolitsch, A. Chuvilin, U. Kaiser, J. Ebert, S. Jakobs, A. Kaless, S. Wüthrich, O. Treichel, B. Wunderlich, M. Bitzer, M. Grössl, Thin Solid Films 517, 6058 (2009)

22. U. Wiedmann, P. Gallion, and G.-H. Duan, J. Lightwave Technol. 16, 1343 (1998)

23. G. Stoney, Proc. R. Soc. London, Ser. A 82, 172 (1909).

24. T. Begou, H. Krol, D. Stojcevski, F. Lemarchand, M. Lequime, C. GrezesBesset, J. Lumeau, Proc. SPIE 9627, $96270 R$ (2015).

25. M. Nordin, M. Larsson, T. Joelsson, J. Birch, and L. Hultman, J. Vac. Sci. \& Tech. A 18, 2884 (2000). 
1. Milton Ohring, Materials science of thin films (1992)

2. https://www.ligo.caltech.edu/news/ligo20160211.

3. O. Adriani, S. Albergo, D. Alesini, M. Anania, D. Angal-Kalinin, et al.. Technical Design Report EuroGammaS proposal for the ELI-NP Gamma beam System. LAL/RT 14-63. 2014.

4. C. A. Ur, "Gamma Beam System at ELI-NP", AIP Conference Proceedings 1645,237 (2015).

5. M.-M. de Denus-Baillargeon, T. Schmitt, S. Larouche, and L. Martinu, "Design and fabrication of stress-compensated optical coatings: FabryPerot filters for astronomical applications," Appl. Opt. 53, 2616-2624 (2014)

6. Ying Wang, Yue-guang Zhang, Wei-lan Chen, Wei-dong Shen, Xu Liu, and Pei-fu Gu, "Optical properties and residual stress of YbF3 thin films deposited at different temperatures," Appl. Opt. 47, C319-C323 (2008)

7. Martin Bischoff, Tobias Nowitzki, Oliver Voß, Steffen Wilbrandt, and Olaf Stenzel, "Postdeposition treatment of IBS coatings for UV applications with optimized thin-film stress properties," Appl. Opt. 53, A212-A220 (2014)

8. F Richter, H Kupfer, P Schlott, T Gessner, C Kaufmann, "Optical properties and mechanical stress in $\mathrm{SiO} 2 / \mathrm{Nb} 2 \mathrm{O} 5$ multilayers," Thin Solid Films Volume 389, Issues 1-2, 15 June 2001, Pages 278-283

9. J. B. Oliver, P. Kupinski, A. L. Rigatti, A. W. Schmid, J. C. Lambropoulos, S. Papernov, A. Kozlov, C. Smith, and R. D. Hand, "Stress compensation in hafnia/silica optical coatings by inclusion of alumina layers", Opt. Express 20, 16596-16610 (2012)

10. F. Lemarquis, "Athermal compensation of the stress induced surface deflection of optical coatings using isoadmittance layers," Appl. Opt. 53, A229-A236 (2014).

11. T. Begou, H. Krol, D. Stojevski, F. Lemarchand, M. Lequime, C. GrezesBesset and J. Lumeau, "Complex optical interference filters with stress compensation for space applications", CEAS Space J (2017). doi:10.1007/s12567-017-0149-5

12. Tatiana Amotchkina, Michael K. Trubetskov, Yurij Pervak, Laszlo Veisz, and Vladimir Pervak, "Stress compensation with antireflection coatings for ultrafast laser applications: from theory to practice," Opt. Express 22, 30387-30393 (2014)

13. R. Willey, "Procedure for Designing Optical Coatings to Control Stress," Society of Vacuum Coaters Annual Technical Conference Proceedings, 57 (2014)

14. Robert B. Sargent and Nada A. O'Brien, Dielectric Materials for Thin-FilmBased Optical Communications Filters, MRS Bulletin Volume 28, Issue 5 (Photonic Materials for Optical Communications), pp. 372-376, May 2003.

15. T. Begou, F. Lemarchand and J. Lumeau, "Advanced optical interference filters based on metal and dielectric layers", Optics Express 24(18), 20925-20937 (2016).

16. M. Scherer, J. Pistner, W. Lehnert, "UV- and VIS Filter Coatings by Plasma Assisted Reactive Magnetron Sputtering (PARMS)", OIC 2010 Proceedings.

17. A. Zoeller, M., H. Hagedorn, W. Klug and C. Schmitt, "High accurate in-situ optical thickness monitoring", OIC 2004 Proceedings.

18. S. Jakobs, M. Lappschies, U. Schallenberg, O. Stenzel, and S. Wilbrandt, "Characterization of metal-oxide thin films deposited by plasma-assisted reactive magnetron sputtering", Chinese Optics Letters 8, 1-5 (2010)

19. Cheng-Chung Lee, Chuen-Lin Tien, and Jin-Cherng Hsu, "Internal stress and optical properties of $\mathrm{Nb2} 25$ thin films deposited by ion-beam sputtering," Appl. Opt. 41, 2043-2047 (2002)

20. R. Chow, M.A. Schmidt, A.W. Coombs, J. Anguita, M.J. Thwaites, "Niobium Oxide Film Deposition Using a High-Density Plasma Source", 49th Annual SVC Technical Conference Washington, DC, United States, April 22, 2006 through April 27, 2006

21. O. Stenzel, S. Wilbrandt, N. Kaiser, M. Vinnichenko, F. Munnik, A. Kolitsch, A. Chuvilin, U. Kaiser, J. Ebert, S. Jakobs, A. Kaless, S. Wüthrich, O. Treichel, B. Wunderlich, M. Bitzer, M. Grössl, "The correlation between mechanical stress, thermal shift and refractive index in $\mathrm{HfO} 2, \mathrm{Nb2O} 5, \mathrm{Ta} 2 \mathrm{O} 5$ and $\mathrm{SiO} 2$ layers and its relation to the layer porosity", Thin Solid Films 517, 60586068 (2009)

22. Uwe Wiedmann, Philippe Gallion, and Guang-Hua Duan, "A Generalized Approach to Optical Low-Coherence Reflectometry Including Spectral Filtering Effects," J. Lightwave Technol. 16, 1343- (1998)

23. G. Stoney, The tension of metallic films deposited by electrolysis, Proc. R. Soc. London, Ser. A 82, 172 (1909).

24. T. Begou, H. Krol, D. Stojcevski, F. Lemarchand, M. Lequime, C. GrezesBesset, J. Lumeau, "Complex optical interference filter with stress compensation", SPIE 9627, Optical Systems Design 2015: Advances in Optical Thin Films V, 96270R (23 September 2015).

25. M. Nordin, M. Larsson, T. Joelsson, J. Birch, and L. Hultman, "Residual stress formation in multilayered TiN/TaN $x$ coatings during reactive 